\section{Does the Use of Reservoirs Have Any Impact on the Efficacy of At-Home Bleaching? A Systematic Review}

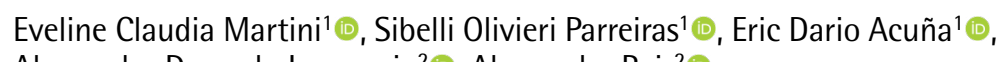
Alessandro Dourado Loguercioº ${ }^{-}$, Alessandra Reis² ${ }^{2}$

\author{
'Department of Restorative Dentistry, \\ UEPG - Universidade Estadual de \\ Ponta Grossa, Ponta Grossa, PR, Brazil \\ ${ }^{2} \mathrm{~S}$ chool of Dentistry, UEPG - \\ Universidade Estadual de Ponta \\ Grossa, Ponta Grossa, PR, Brazil \\ Correspondence: Profa. Dra. \\ Alessandra Reis, Rua Carlos \\ Cavalcanti, 4748 Bloco M, Sala \\ 64-A, 84030-900, Ponta Grossa, PR, \\ Brazil; Tel: +55-42-9 9903-0101. \\ e-mail: reis_ale@hotmail.com
}

\begin{abstract}
To answer the following focused question through a systematic review: "Are the risk and intensity of tooth sensitivity (TS) and bleaching efficacy different between adult patients who undergo at-home bleaching using trays with reservoirs and those who use trays without reservoirs?". A comprehensive search was performed in the MEDLINE via PubMed, Scopus, Web of Science, Latin American and Caribbean Health Sciences Literature database, Brazilian Library in Dentistry, Cochrane Library, and grey literature without restrictions. Abstracts from conferences; unpublished and ongoing trial registries, dissertations and theses (ProQuest Dissertations and Periódicos Capes Theses databases) were searched. Only randomized clinical trials (RCTs) were included. We used the Risk of Bias tool (RoB) from the Cochrane Collaboration for quality assessment. After the removal of duplicates, title and abstract screening and full-text examination, nine RCTs remained for qualitative analyses. The great majority of the studies did not report the method of randomization, allocation concealment, and examiner blinding during color assessment. From the nine studies, eight were at unclear risk of bias. In regard to color change, four studies reported no change and two reported improved color change with reservoirs. Only four studies recorded tooth sensitivity and they reported no significant differences. Only one study reported greater gingival irritation with reservoirs. Lack of data reporting prevented us from running a meta-analysis. Further well-designed RCT should be conducted to answer this research question. So far there is not evidence to support that reservoirs in bleaching trays improve color change. PROSPERO - CRD42016037628
\end{abstract}

Key Words: systematic review, reservoirs, at-home bleaching, dental sensitivity.

\section{Introduction}

Since its introduction by Haywood and Heymann (1), at-home dental bleaching has been the most commonly used method for tooth whitening. This technique is effective and simple for whitening extrinsically stained or discolored teeth (2-4). At-home bleaching has some advantages, such as ease of application, reduced chair time and costs, high success rates (5-8), and safety of materials used (8-12).

This technique requires the use of low hydrogen peroxide or carbamide peroxide concentrations placed into a custom-fabricated tray. The tray is worn from $30 \mathrm{~min}$ to $8 \mathrm{~h}$ per day or overnight for approximately 3 to 6 weeks. Some variations in the bleaching tray can be found in the literature, such as the type of thermoplastic material used for its fabrication and the presence or absence of reservoirs. The use of tray reservoirs was first introduced by Fischer (13). For such purpose, light-cured block-out resin spacers or even light-curing composite resins are applied on the buccal surface of teeth from the cast models to create an additional space between the tray and the teeth.

Some authors $(14,15)$ report that bleaching trays with reservoirs increase the amount of available product for bleaching and allow for a complete seating of the bleaching tray, mainly when used with more viscous whitening materials (14). However, the benefits of adding a reservoir in bleaching trays are still unclear, and different results have been reported. For example, while researchers in one study observed a significantly higher degree of whitening for bleaching trays with reservoirs (16), others did not observe any benefit $(15,17-21)$, still finding trays with reservoirs were found to be considered harmful for soft tissues due to the observed higher risk of gingival irritation (22).

We cannot rule out the fact that the lack of differences between groups with and without reservoirs could be due to the low power of these studies. Negative findings of underpowered studies do not allow one to conclude that groups are not different from one another, but rather, these results may simply be due to chance. By combining the results of small clinical trials with low risk of bias, we can have a more precise estimate of any difference between at-home bleaching procedures with and without reservoirs.

Therefore, the aim of this study was to determine whether there are evidence-based differences in tooth sensitivity and degree of color change of at-home bleaching performed with bleaching trays with and without reservoirs. For this purpose, we aimed to answer the following PICO 
question (population, intervention, comparison, and outcome): "Are the risk and intensity of tooth sensitivity, as well as bleaching efficacy, different between adult patients who undergo at-home bleaching using trays with reservoirs and those who use trays without reservoirs?"

\section{Material and Methods}

\section{Protocol and Registration}

This study protocol was registered at the International Prospective Register of Systematic Reviews (PROSPERO CRD42016037628) and followed the recommendations of the Preferred Reporting Items for Systematic Reviews and Meta-Analyses (PRISMA) statement for report.

\section{Eligibility Criteria}

Parallel and split-mouth randomized clinical trials (RCT) that compared at-home bleaching in adult patients of any age with and without reservoirs were included. RCTs that evaluated only one of the techniques was excluded.

\section{Search Strategy and Information Sources}

The controlled vocabulary (MeSH terms) and free keyword were used in the search strategy based on the the risk of gingival inflammation (secondary outcome).

We searched in electronic databases (MEDLINE via PubMed, Latin American and Caribbean Health Sciences Literature database (LILACS), Brazilian Library in Dentistry (BBO), and Cochrane Library) and citation databases (Scopus, Web of Science) (Fig. 1). The reference lists of all primary studies were hand searched for additional relevant publications. No restrictions to publication date or languages were imposed. The date of the update search is described in Table 1.

Gray literature was also searched. The abstracts of the annual conference of the International Association for Dental Research (IADR) and their regional divisions (1990-2018), the database System for Information on Grey Literature in Europe (OpenSigle), dissertations and theses (ProQuest Dissertations and Periódicos Capes Theses database), were also examined. Whenever an abstract in conference meeting was found, we tried to find the full-text by searching or by contacting the study authors.

Unpublished and ongoing trials were searched in the clinical trials registries: Current Controlled Trials (www. controlled-trials.com), International Clinical trials registry platform (http://apps.who.int/trialsearch/), ClinicalTrials. gov (www.clinicaltrials.gov), Rebec (www.rebec.gov.br), and
EU Clinical Trials Register (https://www.clinicaltrialsregister. eu).

\section{Study Selection and Data Collection Process}

After database collection, data from each database were exported to the EndNote reference manager software (X6, Thomson Reuters, USA). Duplicates were then removed in a two-step procedure. In the first step, a specific tool from the EndNote to remove duplicates were used. However, this tool cannot remove all duplicates due to differences in the indexation process used in the different databases. In the second step, articles were alphabetically organized by title and duplicates could be identified and removed manually.

Then, articles were screened by title and abstracts according to the eligibility criteria. Full-text articles were obtained when the title and abstract presented insufficient information to make a clear decision. Subsequently three reviewers (E.M., S.P. and E.A.) classified those that met the inclusion criteria. A study ID was given for each eligible study, combining first author and year of publication.

Relevant information about the study design, participants, interventions, and outcomes were extracted using customized extraction forms by three authors in an independent manner. When data from multiple bleaching sessions were provided, we averaged the data of the same group. When more than one bleaching agent from the same bleaching protocol was included in the study, their values were merged to make a single entry. Concerning color change, we collected data that represented the most immediate result (up to three months after bleaching) and we used the same rule for tooth sensitivity (up to 1 week after bleaching).

\section{Risk of Bias in Individual Studies}

As well as data extraction, assessment of the risk of bias of the included trials were evaluated by three independent reviewers, using the Cochrane Collaboration's tool for assessing risk of bias in randomized trials (23). The assessment criteria contained six items: sequence generation, allocation concealment, blinding of the outcome assessors, incomplete outcome data, selective outcome reporting, and other sources of bias. This latter one was not assessed in the present study. During data extraction and assessment of the risk of bias, any disagreements between the reviewers were resolved through discussion, and if needed, by consulting a third reviewer.

For each domain of the quality assessment, the risk of bias was scored following recommendations as described in the Cochrane Handbook for Systematic reviews of Interventions 5.1.0 (http://handbook.cochrane.org). The judgment for each entry involved judgements of low risk of bias, high risk of bias or 'unclear' risk, indicating either lack of information or uncertainty over the potential for bias. 


\begin{tabular}{|c|c|c|}
\hline \multicolumn{3}{|c|}{ Pubmed ( $8^{\text {th }}$ October 2018) } \\
\hline$\# 1$ & $\# 2$ & \#3 \\
\hline $\begin{array}{l}\text { tooth discoloration [MeSH Terms] OR color } \\
\text { [title/abstract] OR "tooth discoloration" } \\
\text { [title/abstract] OR "tooth staining" [title/ } \\
\text { abstract] OR "stained tooth" [title/abstract] } \\
\text { OR “stained teeth" [title/abstract] OR } \\
\text { "tooth discolouration" [title/abstract] } \\
\text { OR “teeth discolouration" [title/abstract] } \\
\text { OR “discolored tooth" [title/abstract] } \\
\text { OR “discolored teeth" [title/abstract] OR } \\
\text { "discoloured tooth" [title/abstract] OR } \\
\text { "discoloured teeth" [title/abstract] OR } \\
\text { “dental discoloration" [title/abstract]OR } \\
\text { "dental discolouration" [title/abstract] }\end{array}$ & $\begin{array}{l}\text { Peroxides [MeSH Terms] OR tooth bleaching } \\
\text { [MeSH Terms] OR tooth bleaching agents } \\
\text { [MeSH Terms] OR hydrogen peroxide } \\
\text { [MeSH Terms] OR carbamide peroxide } \\
\text { [Supplementary Concept]) OR peroxides } \\
\text { [title/abstract] OR "hydrogen peroxide" [title/ } \\
\text { abstract] OR "carbamide peroxide" [title/ } \\
\text { abstract] OR tray [title/abstract] OR trays } \\
\text { [title/abstract] OR reservoir [title/abstract] } \\
\text { OR reservoirs [title/abstract] OR whitening } \\
\text { [title/abstract] OR bleaching [title/abstract] } \\
\text { OR "home-use" [title/abstract] OR nightguard } \\
\text { [title/abstract] OR "at-home" [title/abstract] }\end{array}$ & $\begin{array}{l}\text { randomized controlled trial [pt] OR } \\
\text { controlled clinical trial [pt] OR randomized } \\
\text { controlled trials [mh] OR random allocation } \\
\text { [mh] OR double-blind method [mh] OR } \\
\text { single-blind method [mh] OR clinical trial } \\
\text { [pt] OR clinical trials [mh] OR (“clinical } \\
\text { trial” [tw]) OR ((singl*[tw] OR doubl*[tw] } \\
\text { OR trebl*[tw] OR tripl*[tw]) AND (mask*[tw] } \\
\text { OR blind*[tw])) OR (placebos[mh] OR } \\
\text { placebo*[tw] OR random*[tw] OR research } \\
\text { design [mh:noexp] OR comparative } \\
\text { study [pt] OR evaluation studies as topic } \\
\text { [mh] OR follow-up studies [mh] OR } \\
\text { prospective studies [mh] OR control* [tw] } \\
\text { OR prospective* [tw] OR volunteer* [tw]) } \\
\text { NOT (animals [mh] NOT humans [mh])) }\end{array}$ \\
\hline \multicolumn{3}{|c|}{$\begin{array}{c}\# 1 \text { AND \#2 } \\
\text { Scopus ( } 8^{\text {th }} \text { October 2018) }\end{array}$} \\
\hline $\begin{array}{l}\text { \#1 TITLE-ABS-KEY (“tooth discoloration”) } \\
\text { OR TITLE-ABS-KEY (“tooth staining”) } \\
\text { OR TITLE-ABS-KEY (“stained tooth”) OR } \\
\text { TITLE-ABS-KEY (“discolored tooth”) OR } \\
\text { TITLE-ABS-KEY (“dental discoloration”) }\end{array}$ & \multicolumn{2}{|c|}{$\begin{array}{l}\text { \#2 TITLE-ABS-KEY (“peroxide”) OR TITLE-ABS-KEY (“hydrogen peroxide”) OR TITLE-ABS- } \\
\text { KEY (“carbamide peroxide”) OR TITLE-ABS-KEY (“tray”) OR TITLE-ABS-KEY (“reservoir”) } \\
\text { OR TITLE-ABS-KEY (“whitening”) OR TITLE-ABS-KEY (“bleaching”) OR TITLE-ABS-KEY } \\
\text { (“home-use”) OR TITLE-ABS-KEY (“nightguard”) OR TITLE-ABS-KEY (“at-home”) }\end{array}$} \\
\hline \multicolumn{3}{|c|}{$\begin{array}{l}\# 1 \text { AND \#2 } \\
\text { cience }\left(8^{\text {th }} \text { October } 2018\right)\end{array}$} \\
\hline \multicolumn{3}{|c|}{$\begin{array}{l}\text { f Science }\left(8^{\text {th }} \text { October } 2018\right) \\
\text { \#2TS=(peroxides) OR TS=(“hydrogen peroxide”) OR TS=(“carbamide peroxide” } \\
\text { OR TS=(tray*) OR TS=(reservoir*) OR TS=(whitening) OR TS=(bleaching) } \\
\text { OR TS=("home-use") OR TS=(nightguard) OR TS=(“at-home”) }\end{array}$} \\
\hline \multicolumn{3}{|c|}{$\begin{array}{c}\# 1 \text { AND \#2 } \\
\text { LILACS and BBO ( } 8^{\text {th }} \text { October 2018) }\end{array}$} \\
\hline 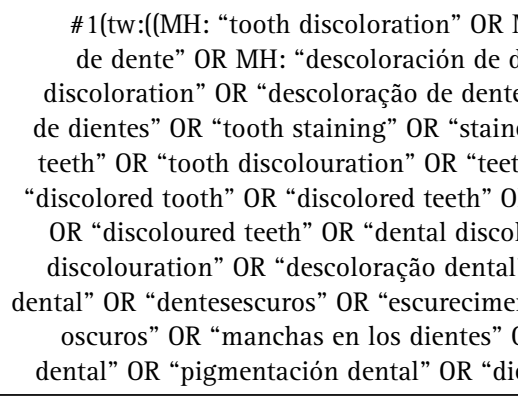 & $\begin{array}{lc}\text { H: "descoloração } & \text { \#2(tw:((MH: "peroxic } \\
\text { ntes" OR “tooth } & \text { bleaching agents" OR } \\
\text { OR "descoloración } & \text { "tooth bleaching" OR } \\
\text { tooth" OR "stained } & \text { dientes" OR "tooth } \\
\text { discolouration" OR } & \text { OR "blanqueadore } \\
\text { "discoloured tooth" } & \text { "hydrogen peroxide" } \\
\text { ration" OR "dental } & \text { hidrógeno" OR "carb } \\
\text { OR "manchamento } & \text { OR "clareamento cas } \\
\text { o dental" OR "dientes } & \text { OR "moldeira de clar } \\
\text { "oscurecimiento } & \text { "reservoirs" OR "res } \\
\text { tes pigmentados"))) } & \text { OR "bleaching" OR } \\
\end{array}$ & 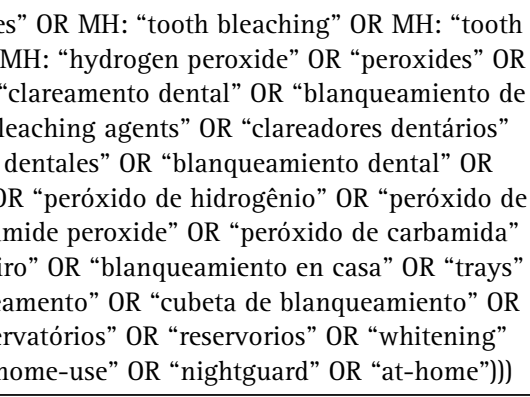 \\
\hline \multicolumn{2}{|r|}{ Cochrane Library ( $8^{\text {th }}$ October 2018 ) } & \\
\hline $\begin{array}{r}\text { \#1 MeSH descriptor: [Tooth Disco } \\
\text { \#2 “tooth staining”: ti,ab,kw (Word ve } \\
\text { \#3 stained near t??th :ti,ab,kw (Word } \\
\text { \#4 discol*red near t??th:ti,ab,kw (Word } \\
\text { \#5 dental near discol"ration:ti,ab,kw (Wor } \\
\text { \#6 - \#1 or \#2 or \#3 } \\
\text { \#7MeSH descriptor: [Peroxid } \\
\text { \#8MeSH descriptor: [Tooth Blea } \\
\text { \#9MeSH descriptor: [Tooth Bleachir } \\
\text { \#10MeSH descriptor: [Hydrogen P } \\
\text { \#11 “carbamide peroxide": ti,ab,kw (Wor } \\
\text { \#12 tray?:ti,ab,kw (Word variati } \\
\text { \#13 reservoir?:ti,ab,kw (Word varia }\end{array}$ & $\begin{array}{l}\text { ration] explode all trees } \\
\text { lations have been searched) } \\
\text { riations have been searched) } \\
\text { ariations have been searched) } \\
\text { variations have been searched) } \\
\text { \#4 or \#5 } \\
\text { ] explode all trees } \\
\text { ing] explode all trees } \\
\text { Agents] explode all trees } \\
\text { oxide] explode all trees } \\
\text { variations have been searched) } \\
\text { s have been searched) } \\
\text { ons have been searched) }\end{array}$ & $\begin{array}{l}\text { \#14 “whitening”: ti,ab,kw (Word } \\
\text { variations have been searched) } \\
\text { \#15 "bleaching": ti,ab,kw (Word } \\
\text { variations have been searched) } \\
\text { \#16 "home use": ti,ab,kw (Word } \\
\text { variations have been searched) } \\
\text { \#17 “nightguard": ti,ab,kw (Word } \\
\text { variations have been searched) } \\
\text { \#18 "at home": ti,ab,kw (Word } \\
\text { variations have been searched) }\end{array}$ \\
\hline
\end{tabular}

Figure 1. Electronic database and search strategy. 
At the study level, studies were judged at "low" risk of bias if there was adequate sequence generation, allocation concealment and operator blinding (key domains of the Cochrane risk of bias tool). If at least one of these domains were considered "unclear", the study received the same judgment. On the other hand, if at least one key domain was at high risk of bias, the study was judged as "high" risk.

\section{Summary Measures and Synthesis of the Results}

Tables and figures were created to synthesize the results. We attempted to collect results about color change, risk and intensity of tooth sensitivity and gingival irritation. Authors were not contacted for further information due to the fact that empirical evidence shows a low response rate in articles published more than a decade ago.

\section{Results}

\section{Study Selection}

After the database screening and removal of duplicates, 2523 studies were identified. After title screening, 189 studies remained, and this number was reduced to nine after a careful examination of their abstracts. Of these nine, two were abstracts published by the International Association for Dental Research (IADR) $(16,17)$ and one was registered in REBEC (Brazilian Registry of Clinical Trials) (24) (Fig. 2).

\section{Characteristics of Included Articles}

The characteristics of the studies selected are listed in Table 1. A split-mouth study design was used in eight studies, and a parallel design was used in only one study (16). For color evaluation, three studies involved the use of shade guides, although data were not reported or were poorly reported in the results section $(15,17,19)$. Subjective description of the findings, based on photographs or clinical observations, was used in three studies $(18,20,25)$. Three other studies used an objective instrument (spectrophotometer or colorimeter) for color assessment $(15,16,24)$, and one did not evaluate color changes (22).

The number of patients included in these studies was small and ranged from 5 to 36 participants. There was a high variability in the participants' age. While some studies predominantly included young adult patients (18 to 40 years old $)(16,18,22,25)$ others included elderly patients as well (19 to 68 years old) $(15,16,19,20)$. This information was not reported in the study of Bosma et al. (17). In one study, males were the majority of the participants (22); in 4 other articles, females predominated $(15,19,20,25)$, and in the remaining 3, this information was not reported (16-18).

The bleaching protocol was different among the studies. Four studies used 10\% carbamide peroxide for at-home bleaching $(19,20,24,25)$, and four studies used carbamide peroxide with higher concentrations, such as
$15 \%(15,20), 16 \%(20,22)$ and $20 \%(20)$. Only two studies used hydrogen peroxide for at-home bleaching $(18,20)$. The type of bleaching agent and concentration was not reported in two studies $(16,17)$. The daily duration of use of the at-home bleaching gel varied from 2 to $8 \mathrm{~h}$ per day. In one study, the gel was used twice a day (19). The number of treatment days varied from 10 to 30 days.

Four studies did not evaluate the risk of tooth sensitivity $(16,17,20,22)$. As for gingival irritation, we could not find this information in seven out of nine primary studies (15$18,20,22,25)$. Kirsten et al $(22)$ classified the inflammation of the gingival tissue via histological evaluation. Only one study evaluated the risk and intensity of tooth sensitivity and gingival irritation (24).

\section{Main Findings}

The main findings of the eligible studies are described in Table 2. One may observe a lack of data reporting and the use of adequate instruments for evaluation of color change and the risk and intensity of tooth sensitivity. Description of summary measures and variance of the data was rarely reported. The study of Martini et al (24) was found in a clinical trial registry as protocol and the data were not collected yet.

Regarding color evaluation, only three studies reported color changes using statistical evaluation $(15,16)$. The other studies performed a qualitative description of color changes. Two studies did not evaluate color change $(22,25)$; four reported that changes were not observed $(17,18,19,20)$, two reported that reservoirs improved color change $(15,16)$ and one study have not collected data yet (24).

In regard to tooth sensitivity, four studies did not evaluate this outcome $(16-18,22)$, one did not collected this data yet (24) and the remaining reported similar tooth sensitivity between the groups $(15,19,20,25)$ and were similar in both groups (25). For gingival irritation, four studies did not evaluate this outcome $(16,18,20,25)$, three studies did not observe any difference between groups $(15,17,19)$ and only 1 reported greater inflammation in the group with reservoirs (22).

\section{Assessment of the Risk of Bias}

The risk of bias of the selected studies is presented in Figure 3. Except for the study of Bosma (17) and Martini (24), which reported the method of randomization, the other studies did not report the method of randomization or did not perform it correctly $(15,16,18-20,22,25)$. Allocation concealment and examiner blinding during color assessment were also missing in the studies. Another important issue is the selective reporting observed in some studies that did not report color change and/or tooth sensitivity $(17,20,22,25)$. In summary, of the 9 studies, 8 were at unclear risk of bias. 


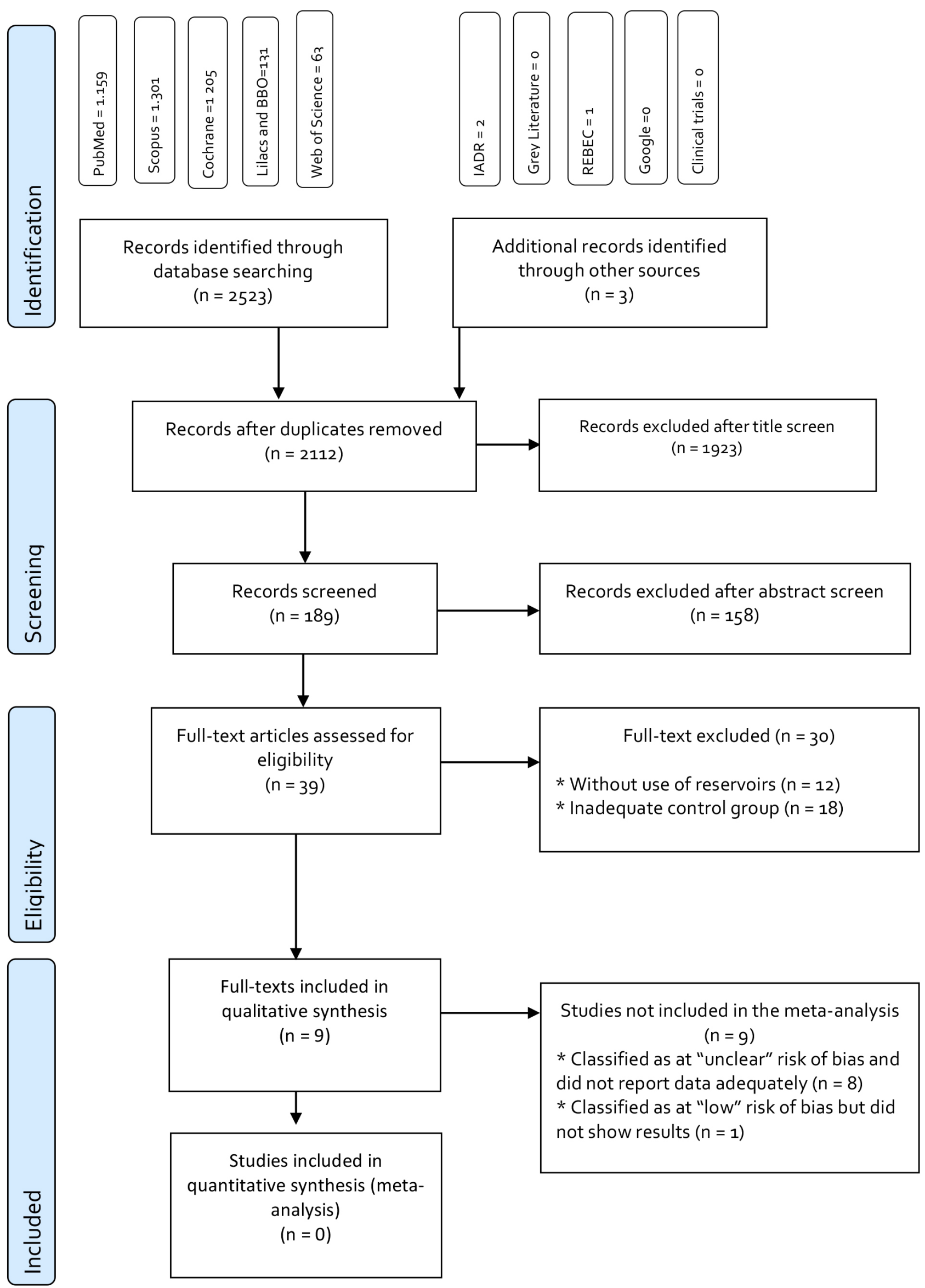




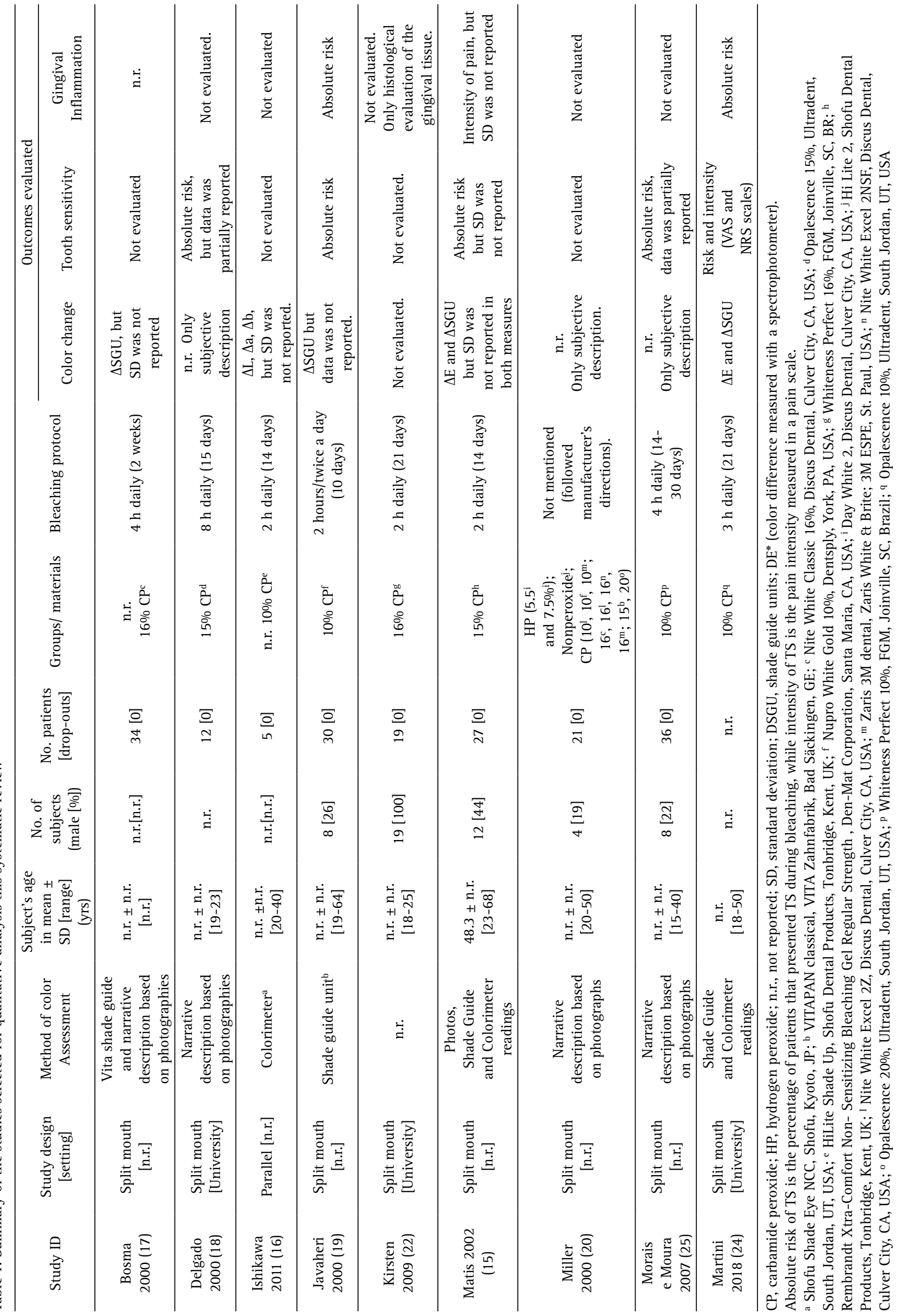




\section{Discussion}

Meta-analysis is usually performed in systematic reviews to obtain a statistical summary and an estimate of the effect size for the study problem. However, the meta-analysis will never be better than the primary studies included. Surprisingly, the great majority of the studies from the present review were at unclear risk of bias, which reduced the reliability of the study findings reported by authors and described in Table 2.

Some important aspects of well-designed clinical studies were missing in the eligible studies of the present study, such as randomization, allocation concealment, and blinding. Randomization, when correctly performed, allows a patient or a patient's side mouth to be allocated in either the test or control group, controlling for both known and unknown prognostic factors (23). Among the primary studies of this systematic review, we observed that adequate sequence generation was not performed in most of them $(18,20,25)$. Only one study (17) reported that a random sequence was generated by computer, however without further details. In other two studies $(15,24)$, the authors reported that the study was randomized, but the method of randomization was not clear.

As important as randomization, allocation concealment is necessary to protect the randomization process since the treatment to be allocated is not known before the patient is

Table 2. Summaries of the main findings of the articles included in the qualitative analysis

\begin{tabular}{|c|c|c|c|}
\hline \multirow[b]{2}{*}{ Study ID } & \multicolumn{3}{|c|}{ Description of the results } \\
\hline & Color change & Tooth sensitivity & $\begin{array}{c}\text { Gingival } \\
\text { Inflammation }\end{array}$ \\
\hline $\begin{array}{l}\text { Bosma } \\
2000(17)\end{array}$ & $\begin{array}{l}\text { Subjective description through } \\
\text { photos with a reduction of } 5.6 \\
\text { color units in the } 2 \text { groups, without } \\
\text { significant differences (p>0.05). }\end{array}$ & Not evaluated & Not observed in any group. \\
\hline $\begin{array}{l}\text { Delgado } \\
2000(18)\end{array}$ & $\begin{array}{l}\text { Subjective description through } \\
\text { photos. The authors concluded that } \\
\text { the groups were not different. }\end{array}$ & $\begin{array}{l}\text { Only one patient reported tooth } \\
\text { sensitivity and was treated with } \\
1.1 \% \text { NaF. No measurement in pain } \\
\text { scale was reported by the authors. }\end{array}$ & Not evaluated \\
\hline $\begin{array}{l}\text { Ishikawa } \\
\text { 2011(16) }\end{array}$ & $\begin{array}{l}5 \text { patients were evaluated through } \\
\text { objective color measurement. } 8 \\
\text { units of color on the side with } \\
\text { reservoirs and } 6.8 \text { on the side } \\
\text { without reservoirs }(p<0.05) .\end{array}$ & Not evaluated & Not evaluated \\
\hline $\begin{array}{l}\text { Javaheri } \\
2000(19)\end{array}$ & $\begin{array}{l}30 \text { patients evaluated with subjective } \\
\text { color measurement, no difference } \\
\text { between sides was noted and no } \\
\text { statistical analysis was performed. }\end{array}$ & $\begin{array}{l}\text { None of the patients reported } \\
\text { tooth sensitivity. }\end{array}$ & $\begin{array}{l}\text { None of the patients reported } \\
\text { irritation in the mucosa.. }\end{array}$ \\
\hline $\begin{array}{l}\text { Kirsten } \\
2009 \text { (22) }\end{array}$ & Not evaluated. & Not evaluated. & $\begin{array}{l}19 \text { patients evaluated, sides with } \\
\text { reservoir increase of inflammation } \\
\text { only immediately after bleaching (p } \\
=.0075) \text {. Differences were found in } \\
\text { the inflammation intensity between } \\
\text { groups immediately after and } 45 \\
\text { days after bleaching }(\mathrm{p}<0.01) . \\
\text { Mild inflammation in the group } \\
\text { without reservoir and moderate } \\
\text { inflammation with a reservoir. }\end{array}$ \\
\hline Matis 2002 (15) & $\begin{array}{l}\text { Group with reservoirs had } \\
\text { significantly higher } \Delta \mathrm{E} \text { than } \\
\text { group without reservoirs in } \\
\text { all time assessments }(\mathrm{p}<0.01) \text {, } \\
\text { except week } 6(\mathrm{p}=0.11) .\end{array}$ & No significant difference $(\mathrm{p}=0.90)$. & No significant difference $(\mathrm{p}=0.46)$. \\
\hline Miller 2000 (20) & $\begin{array}{l}\text { Subjective description } \\
\text { through photos and without } \\
\text { differences between groups. }\end{array}$ & No significant difference. & Not evaluated. \\
\hline $\begin{array}{l}\text { Morais e Moura } \\
2007 \text { (25) }\end{array}$ & Not evaluated. & $\begin{array}{l}18^{\text {th }} \text { day only - same tooth } \\
\text { sensitivity in both groups. }\end{array}$ & Not evaluated. \\
\hline $\begin{array}{l}\text { Martini } \\
2018(24)\end{array}$ & $\begin{array}{l}\text { Results not collected yet (study } \\
\text { found in a clinical trial registry) }\end{array}$ & Results not collected yet & Results not collected yet \\
\hline
\end{tabular}


enrolled into the study (23). The description of the allocation concealment was unclear in eight primary studies, perhaps because the authors did not know its importance at the time the studies were conducted. Both randomization and allocation concealment are essential to minimize selection bias. To clarify whether allocation concealment was done, contact with authors can be established. However, we did not contact them as authors tend to produce only positive answers in regard to the risk of bias, which may not represent the truth $(23,26)$.

Another important issue in clinical trials that prevents another type of bias - performance bias - is blinding of examiner and patient (23). For the focused PICO question evaluated in this study, participant blinding was not possible, as differences between bleaching trays could be easily identified by the participants. However, blinding of the examiner could have been performed. From the nine studies, only one reported that the evaluator was blinded
(24), but this study was a protocol registered in a clinical trial in which results were not available yet. As for the other eight studies already published, this was a serious limitation of the methodology of these studies that further reduces the reliability of the findings.

Apart from the above limitations, which are not much different from what has already been observed in bleaching studies in general (27), the most shocking finding was the lack of standardized methods for reporting important outcomes in bleaching studies, such as color change, risk of tooth sensitivity, and gingival irritation. This fact along with lack of examiner blinding reduces consistently the reliability of the study findings of the eligible studies. Color change is usually evaluated by using either subjective methods (matching with different shade guide units) or objective methods (spectrophotometer or colorimeters). It is reported that measurement with a spectrophotometer provides more accurate results than visual shade matching with shade guides $(28,29)$ as it is less prone to subjective judgments. Only three out of nine primary studies reported the use of objective tools for measurement of primary outcomes $(15,16,24)$. Future clinical trials on bleaching should use a validated instrument to measure color changes, to improve confidence in the results.

Color evaluation by matching with shade guide units was another way to allow for comparison between groups and this procedure was done in three studies $(15,17,19)$. Two out of these three reported changes in shade guide units, but they failed to report measures of data spread (standard deviation or standard error) $(15,17)$. In the third study $(19)$, color change was not reported at all. All other studies, except for the study of Kirsten (22), which did not evaluate color change, only included a narrative description of what was observed in both groups without any further elaboration $(16,18-20,25)$. This poor description of color change does not allow one to conclude via meta-analysis if bleaching trays with reservoirs are more effective or produce faster color change than bleaching trays without reservoirs. The same concern was observed for the outcomes were "risk of tooth sensitivity" and "risk of gingival irritation". These outcomes were not evaluated or were reported inadequately in the great majority of the studies (15-18, $20,22,25)$, which prevents us from making
Figure 3. Summary of the risk of bias assessment according to the Cochrane Collaboration tool. 
any conclusion about the likely side effects of bleaching trays with reservoirs.

Unfortunately, there are several other variables among the primary studies, apart from the presence or absence of reservoirs in the bleaching trays. The low number of studies included in this systematic review prevented us from evaluating the impact of these differences on the results (different protocols, type and concentration of bleaching agents, brand and composition of the product, etc.). The comparison of some of these variables was evaluated in other systematic reviews of the literature. For instance, when carbamide peroxide gels were compared with hydrogen peroxide for at-home bleaching, the former showed better color change (30). Although there are other RCTs that addressed the aforementioned variables, they are still in low number, and their qualities were not addressed yet by systematic reviews of the literature $(12,31,32)$, which may be the subject of future studies.

Although most of the manufacturers do not recommend the creation of reservoirs in bleaching trays, at least one important company that produces bleaching products (Ultradent Products, Inc., Salt Lake, UT, USA) still recommends the fabrication of such reservoirs in bleaching trays for at-home bleaching. Considering that at-home bleaching with reservoirs is more expensive, as it employs more material and requires more time for fabrication of the bleaching trays, it is essential, from a clinical standpoint, to gather information about how worthwhile this method is.

From the findings of the present study, we concluded that there is no reliable evidence to make any conclusion about the efficacy and side effects of bleaching trays with reservoirs compared to bleaching trays without reservoirs, due to the lack of well-designed clinical studies on this subject. Further well-designed randomized clinical trials with good reporting should be performed by carefully following the Consolidate Standards of Reporting Trials (CONSORT) $(27,33)$.

\section{Resumo}

Para responder a seguinte questão de pesquisa através de uma revisão sistemática: "0 risco e a intensidade de sensibilidade dentária (SD) e eficácia de clareamento são diferentes entre pacientes adultos que realizam clareamento caseiro usando moldeiras com reservatórios e aqueles que usam moldeiras sem reservatórios?". Uma pesquisa abrangente foi realizada no MEDLINE via PubMed, Scopus, Web of Science, Literatura LatinoAmericana e do Caribe em Ciências da Saúde (LILACS), Biblioteca Cochrane e literatura cinzenta, sem restrições. Os resumos da conferência anual da Associação Internacional para Pesquisa Dental além de estudos registrados ou em andamento também foram pesquisados. Dissertações e Teses foram pesquisados utilizando o Capes Journal Dissertações e Teses ProQuest. Apenas ensaios clínicos randomizados (ECR) foram incluídos. Usamos a ferramenta Risk of Bias (RoB) da Cochrane para avaliação de qualidade. Após a remoção de duplicatas, triagem de título e resumo e exame de texto completo, nove ECRs permaneceram para análises qualitativas. A grande maioria dos estudos não relatou o método de randomização, ocultação de alocação e cegamento do examinador durante a avaliação de cores.
Dos nove estudos, oito estavam sob risco claro de viés. Em relação à mudança de cor, quatro estudos não relataram nenhuma mudança e dois relataram melhora na mudança de cor com reservatórios. Apenas quatro estudos registraram a sensibilidade dentária e não relataram diferenças significativas. Apenas um estudo relatou maior irritação gengival com reservatórios. A falta de relatórios de dados nos impediu de executar uma meta-análise. Outros ECR bem desenhados devem ser conduzidos para responder a esta questão de pesquisa. Até agora não há evidências que sustentem que reservatórios em moldeiras de clareamento melhorem a mudança de cor. PROSPERO - CRD42016037628

\section{References}

1. Haywood VB, Heymann HO. Nightguard vital bleaching. Quintessence Int 1989;20:173-176.

2. Haywood VB, Leonard RH, Nelson CF, Brunson WD. Effectiveness, side effects and long-term status of nightguard vital bleaching. J Am Dent Assoc 1994;125:1219-1226.

3. Cibirka RM, Myers M, Downey MC, Nelson SK, Browning WD, Hawkins IK, et al. Clinical study of tooth shade lightening from dentistsupervised, patient-applied treatment with two 10\% carbamide peroxide gels. J Esthet Dent 1999;11:325-331.

4. Alonso de la Pena V, Balboa Cabrita 0. Comparison of the clinical efficacy and safety of carbamide peroxide and hydrogen peroxide in at-home bleaching gels. Quintessence Int 2006;37:551-556.

5. Mokhlis GR, Matis BA, Cochran MA, Eckert GJ. A clinical evaluation of carbamide peroxide and hydrogen peroxide whitening agents during daytime use. J Am Dent Assoc 2000;131:1269-1277.

6. Auschill TM, Hellwig E, Schmidale S, Sculean A, Arweiler NB. Efficacy, side-effects and patients' acceptance of different bleaching techniques (OTC, in-office, at-home). Oper Dent 2005;30:156-163.

7. Meireles SS, Heckmann SS, Santos IS, Della Bona A, Demarco FF. A double blind randomized clinical trial of at-home tooth bleaching using two carbamide peroxide concentrations: 6-month follow-up. J Dent 2008;36:878-884.

8. Tay LY, Kose $C$, Herrera DR, Reis A, Loguercio AD. Long-term efficacy of in-office and at-home bleaching: a 2-year double-blind randomized clinical trial. Am J Dent 2012;25:199-204.

9. Giachetti L, Bertini F, Bambi C, Nieri M, Scaminaci Russo D. A randomized clinical trial comparing at-home and in-office tooth whitening techniques: A nine-month follow-up. J Am Dent Assoc 2010;141:1357-1364.

10. Matis BA, Cochran MA, Eckert G, Carlson TJ. The efficacy and safety of a 10\% carbamide peroxide bleaching gel. Quintessence Int 1998;29:555563.

11. Li Y. Peroxide-containing tooth whiteners: an update on safety. Compend Contin Educ Dent Suppl 2000(28):S4-9;quizS48.

12. Meireles SS, Heckmann SS, Leida FL, dos Santos Ida S, Della Bona A, Demarco FF. Efficacy and safety of 10\% and 16\% carbamide peroxide tooth-whitening gels: a randomized clinical trial. Oper Dent 2008;33:606-612.

13. Fischer E. Method for bleaching teeth. US Patent 5098303 Available online: https://patentimages.storage.googleapis.com/7c/03/2c/ fad1f490899245/US5098303.pdf [Latest access January, 11, 2019]

14. Haywood VB, Leonard RH, Jr., Nelson CF. Efficacy of foam liner in $10 \%$ carbamide peroxide bleaching technique. Quintessence Int 1993;24:663-666.

15. Matis BA, Hamdan YS, Cochran MA, Eckert GJ. A clinical evaluation of a bleaching agent used with and without reservoirs. Oper Dent 2002;27:5-11.

16. Ishikawa A TY. Clinical efficiency of home whitening with/without reservoirs. J Dent Res 2011;85((Spec Iss B): \# 174.).

17. Bosma M BJ, Dorfman W, Soo K. Evaluation of a tray fabrication design and effects on vital tooth bleaching. Hilltop Research, Inc Project No 98100673, August 72000.

18. Delgado RJM ML. Nightguard vital bleaching without the addition of spacers to the cast. A simpler and faster, low cost and effective technique. Rev Cienc Odontol 2000;3:41-46. 
19. Javaheri DS, Janis JN. The efficacy of reservoirs in bleaching trays. Oper Dent 2000;25:149-151.

20. Miller MB, Castellanos IR, Rieger MS. Efficacy of home bleaching systems with and without tray reservoirs. Pract Periodontics Aesthet Dent 2000;12:611-614.

21. Geisinger S, Kwon SR, Qian F. Employment of Reservoirs in At-Home Whitening Trays: Efficacy and Efficiency in Tooth Whitening. J Contemp Dent Pract 2015;16:383-388.

22. Kirsten GA, Freire A, de Lima AA, Ignacio SA, Souza EM. Effect of reservoirs on gingival inflammation after home dental bleaching. Quintessence Int 2009;40:195-202.

23. Higgins JP, Altman DG, Gotzsche $P C$, Juni $P$, Moher $D$, Oxman $A D$, et al. The Cochrane Collaboration's tool for assessing risk of bias in randomised trials. BMJ 2011;343:d5928.

24. Martini EC PS, Loguercio AD, Reis A. Evaluation of the presence and absence of reservoirs in a home bleaching tray: randomized, multicenter and blind clinical trial. Brazilian Registry of Clinical Trials (ReBrac); 2018.

25. Morais e Moura R DN, BADINI SRG. Evaluation of the need of internal spacers in a mounthguard for home bleaching technique. Study in vivo. Rev Odonto 2007;15.

26. de Geus JL, Wambier LM, Kossatz S, Loguercio AD, Reis A. At-home vs In-office Bleaching: A Systematic Review and Meta-analysis. Oper Dent 2016;41:341-56.

27. Loguercio AD, Maran BM, Hanzen TA, Paula AMd, Perdigão J, Reis A.
Randomized clinical trials of dental bleaching - Compliance with the CONSORT Statement: a systematic review. Braz Oral Res 2017;31:30.

28. Alsaleh $\mathrm{S}$, Labban $\mathrm{M}$, AlHariri $\mathrm{M}$, Tashkandi E. Evaluation of self shade matching ability of dental students using visual and instrumental means. J Dent 2012;40:82-87.

29. Alshiddi IF, Richards LC. A comparison of conventional visual and spectrophotometric shade taking by trained and untrained dental students. Aust Dent J 2015;60:176-181.

30. Luque-Martinez I, Reis $A$, Schroeder $M$, Munoz MA, Loguercio $A D$, Masterson $D$, et al. Comparison of efficacy of tray-delivered carbamide and hydrogen peroxide for at-home bleaching: a systematic review and meta-analysis. Clin Oral Investig 2016;20:1419-1433.

31. Cardoso PC, Reis A, Loguercio A, Vieira LC, Baratieri LN. Clinical effectiveness and tooth sensitivity associated with different bleaching times for a 10 percent carbamide peroxide gel. J Am Dent Assoc 2010;141:1213-1220.

32. da Costa JB, McPharlin R, Hilton T, Ferracane JI, Wang M. Comparison of two at-home whitening products of similar peroxide concentration and different delivery methods. Oper Dent 2012;37:333-339.

33. Schulz KF, Altman DG, Moher D. CONSORT 2010 statement: Updated guidelines for reporting parallel group randomised trials. J Pharmacol Pharmacother 2010;1:100-107. 